\title{
THE EFFECT OF A BRONCHODILATOR AEROSOL ON VENTILATORY CAPACITY IN FIBROCYSTIC DISEASE OF THE PANCREAS
}

\author{
BY \\ BRYAN GANDEVIA and CHARLOTTE ANDERSON \\ From the Clinical Research Unit, Royal Children's Hospital, Melbourne
}

(RECEIVED FOR PUBLICATION APRIL 27, 1959)

\begin{abstract}
Wheezing is a relatively common symptom or sign in patients with fibrocystic disease of the pancreas and the obstructive nature of their breathing is frequently obvious. Nevertheless, bronchodilator therapy is often not dramatic in its effect and its role has not been clearly defined despite the increasing use of aerosol therapy for the pulmonary aspects of this disease. The aerosol usually contains several constituents, including a bronchodilator drug. As yet no objective evidence has been provided as to the efficacy of the combined therapy or of any individual component.

Modern single-breath tests of ventilatory capacity, which are readily applicable to children, afford accurate and sensitive indices of response to bronchodilator drugs. We have therefore studied the ventilatory capacity of 16 patients immediately before and after a potent bronchodilator aerosol, our aim being to assess the proportion of potentially reversible bronchoconstriction.
\end{abstract}

\section{Methods}

A spirometer of the pattern described by Bernstein, D'Silva and Mendel (1952) and a kymograph with a paper speed of $1.5 \mathrm{~cm}$. per second were used. With the subject seated, the vital capacity (VC) was estimated in the conventional manner and a tracing then made of maximum forced expiration after a full inspiration. The volume of gas expired in the first second of the forced expiration (forced expiratory volume at one second* or FEV $_{1.0}$ ) was measured, the mean of three observations being recorded. The percentage of the vital capacity expired in the first second $\left(\mathrm{FEV}_{1.0} \%\right)$ was then calculated. Predicted values for VC and $\mathrm{FEV}_{\mathbf{1}_{0}}$ were derived from normal standards for children prepared by one of us (Gandevia, 1960). Predictions were based on height; values calculated for age take no account of the small stature of children suffering from fibrocystic disease of the pancreas. In one instance (Case 1), a boy

* The terminology used in this paper is that adopted by the Thoracic Society of Great Britain (Gandevia and Hugh-Jones, 1957). of 17 years, an adult prediction formula based on surface area was used; the study of normal children mentioned above showed this to be appropriate for boys of this age.

An aerosol of $1: 1,000$ isoprenaline (isopropyl-noradrenaline) was administered for one and a half to two minutes, using an effective nebulizer producing a fine mist with an oxygen flow of about 81 ./minute. Approximately two minutes later the tests of ventilatory capacity were repeated. Previous observations in adults have indicated that isoprenaline is a powerful and quick-acting bronchodilator agent and that this duration of administration is adequate to produce a maximum effect* (Hume and Gandevia, 1957a, b; Hume, 1957). Subsequent experience with children has not altered these conclusions. In normal children and in children with funnel chest but no pulmonary symptoms, a bronchodilator aerosol has not produced an increase of more than $5 \%$ in $\mathrm{VC}$ of FEV $_{1 \cdot 0}$.

\section{Clinical Material}

The 16 children studied had been for the most part under observation by one of us (C.A.) for a number of years, their ages ranging from 6 to 17 years. They represented at the time of examination the majority of surviving patients over 5 years of age with fibrocystic disease of the pancreas known to the hospital and may be considered a representative series in this age group. At the time of testing no patient was suffering an exacerbation of pulmonary disease; several were having long-term antibiotic therapy. Individual case histories are summarized in the appendix with particular reference to the severity of pulmonary symptoms. In all cases the diagnosis was considered proven from clinical and investigational data. All but one patient (Case 1) had pancreatic achylia as determined by duodenal intubation; all but this patient also had impaired fat absorption as shown by fat balance studies, and

* We do not wish to imply that isoprenaline is the best preparation for clinical use. Its potency and rapidity of action are responsible for its selection for the present investigation. Therapeutically, its disadvantages when used alone are the frequency of annoying sideeffects and the relatively short duration of its action. 
all but one (Case 2) had raised levels of sodium and chloride in the sweat as determined by the method of Anderson and Freeman (1958). Case 1 showed impaired pancreatic secretion by duodenal intubation but he had a 'positive' sweat test and three siblings with the disease.

On clinical grounds, the patients were divided into groups according to their pulmonary symptoms by one of us (C.A.) without reference to the results of ventilatory capacity studies.

Group 1 (five patients). No persistent cough or sputum was present but there were occasional mild bouts of bronchitis of no greater severity or frequency than might be expected in normal children; there was normal exercise tolerance, and no wheezing was recorded during the years of observation.

Group 2 (six patients). There was clinical evidence of mild persistent or recurrent pulmonary infection with purulent sputum, but little impairment of exercise tolerance or general health. Intermittent wheezing was recorded during the period of observation.

Group 3 (five patients). Severe persistent pulmonary infection was present with purulent sputum, moderately or severely restricted exercise tolerance and intermittent or persistent wheezing.

The children in each group are listed in Table 1 in order of increasing severity of chest symptoms as judged clinically.

\section{Results}

The results of the initial ventilatory capacity studies, together with the change produced by the isoprenaline aerosol, are set out in Table 1, which also shows the age, sex and height for each subject in the three groups. The pre-aerosol values are also shown as a percentage of predicted values; the following summary of the results is most conveniently based chiefly on these figures.

As anticipated on clinical grounds, the overall pattern of abnormality is that of an obstructive ventilatory defect with a normal or low $\mathrm{VC}$, a reduced $\mathrm{FEV}_{1.0}$ and a lowered $\mathrm{FEV}_{1.0} \%$. In Group 1 three patients (Cases 3, 4 and 5) have normal values for all three indices, but in two of these, as with the group as a whole, there is significant increase in $\mathrm{FEV}_{\mathbf{1 . 0}}$ after the aerosol. Case 1 is an exception to the comparative normality of this group in that an $\mathrm{FEV}_{1.0} \%$ of $59.3 \%$ is unequivocally below the normal range, although the $\mathrm{FEV}_{1 \cdot 0}$

TABLE 1

EFFECT OF BRONCHODILATOR AEROSOL ON VENTILATORY CAPACITY OF 16 SUBJECTS WITH FIBROCYSTIC DISEASE OF THE PANCREAS

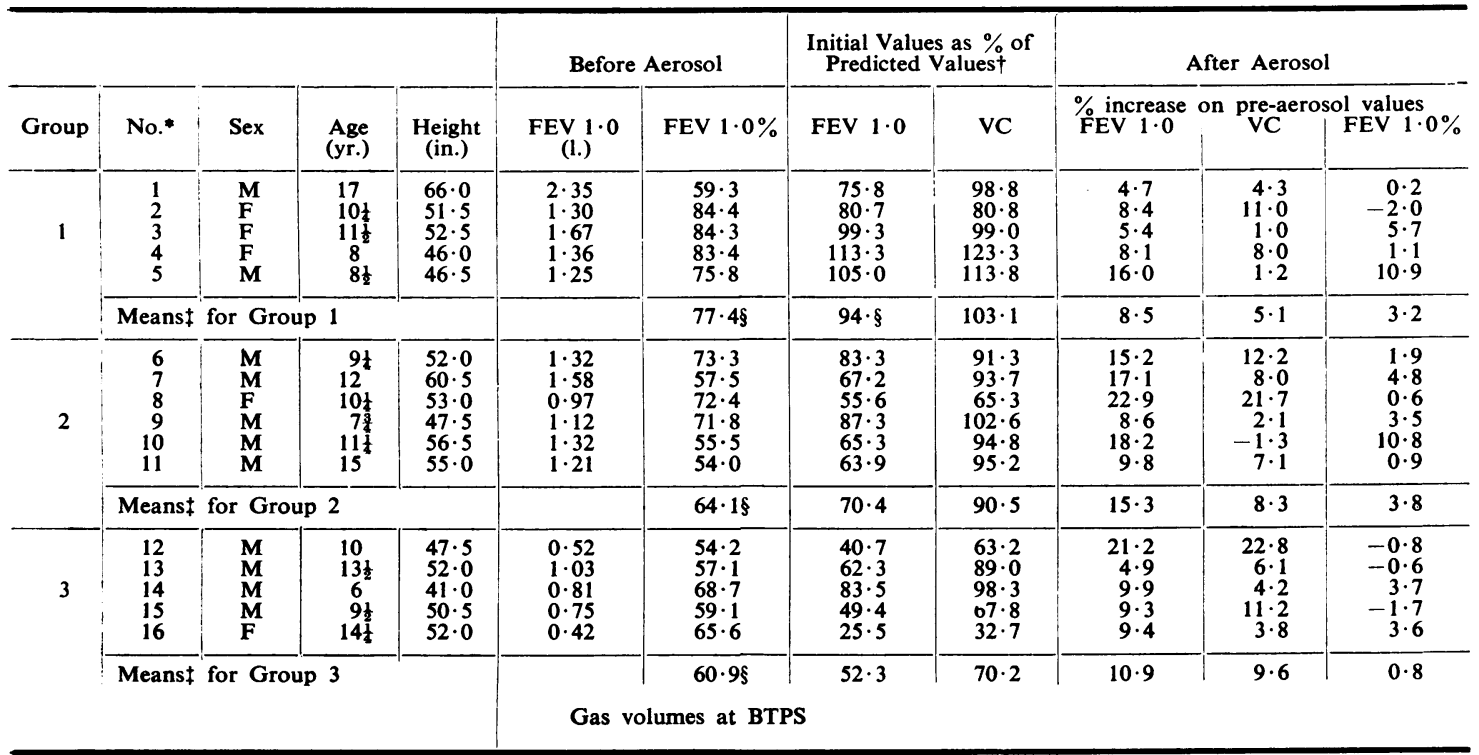

- The children are listed in approximate order of increasing severity of pulmonary symptoms as judged clinically.

+ The adult prediction formula for vital capacity was used in this instance $(2 \cdot 51 . / \mathrm{sq}$. m. of body surface).

$\ddagger$ The means are quoted to help rapid assessment; no purpose is served by attempting to show statistically significant differences between these groups.

\$ Strictly speaking, it is invalid to calculate the mean FEV $1.0 \%$ directly because the predicted values vary slightly with age (Gandevia, in preparation). However, as this variation is small (78\% to $84 \%$ for the age range of this series), its effect is insignificant for present purposes. 
( $2 \cdot 35$ litres) indicates a maximum breathing capacity of over 80 litres per minute. This patient has no clinical evidence of 'bronchitis' or asthma and no restriction of exercise tolerance.

The ventilatory defect is more apparent in Group 2, and is best exemplified by Cases 7, 10 and 11. The group shows little or no reduction in VC, but a considerable fall in $\mathrm{FEV}_{1.0}$ and hence $\mathrm{FEV}_{1.0} \%$. The ventilatory capacity of all members of the group is improved after the bronchodilator aerosol; this is best seen in the striking increase in FEV $_{1.0}$ in Cases 6, 7, 8 and 10. Case 8 indicates one of the fallacies of considering any of the three indices of ventilatory capacity in isolation; $\mathrm{FEV}_{1.0} \%$ is only slightly lowered but there is considerable reduction in both $\mathrm{VC}$ and $\mathrm{FEV}_{1 \cdot 0}$.

In Group 3 ventilatory capacity is further reduced. The impairment is manifest not only in a further fall in the mean $\mathrm{FEV}_{1.0}$ to about half the normal value but also in a marked lowering of the $\mathrm{VC}$. FEV $_{1.0} \%$ thus shows a less striking decrease. With the exception of the least severe case in this group (Case 12) the response to the isoprenaline aerosol was disappointing although significant in three instances. The almost normal results for all indices in Case 14 may be related to inaccurate prediction of the normal values for so short a child.

Comparison of the clinical ranking in the whole series with ranking according to $\mathrm{FEV}_{1 \cdot 0}, \mathrm{FEV}_{1.0} \%$ and VC yields correlation coefficients of 0.586 , 0.516 and 0.414 ; the first two are significant at the $5 \%$ level and approach significance at $1 \%$. The correlation between the increase in $\mathrm{FEV}_{1.0}$ after the aerosol and clinical assessment is negative and of the same order of significance.

\section{Discussion}

In summary, the results show a reasonably good correlation of clinical assessment with ventilatory capacity, although there are individual discrepancies. $\mathrm{FEV}_{1.0}$ and $\mathrm{FEV}_{1.0} \%$, and to a much lesser extent $\mathrm{VC}$, tend to diminish progressively according to the clinical evaluation of severity of pulmonary symptoms and disability. The response to a bronchodilator aerosol is consistently in the direction of improvement; it is most impressive in several children in the intermediate, moderately affected group and least apparent in the most disabled children.

There is little or no improvement in $\mathrm{FEV}_{1.0} \%$ after a bronchodilator aerosol, even in the presence of moderate increases in $\mathrm{FEV}_{1 \cdot 0}$. This finding, which appears anomalous at first sight, is in accord with experience in adults with emphysema or asthma. Thompson and Hugh-Jones (1958) found a sharp increase in $\mathrm{FEV}_{1.0} \%$ after a bronchodilator aerosol only in asthmatic subjects who were already nearly normal at the time of testing; in emphysematous patients or patients severely asthmatic at the time of testing little or no change in $\mathrm{FEV}_{1.0} \%$ was found, irrespective of the degree of improvement in $\mathrm{FEV}_{1 \cdot 0}$ and VC. It is of interest in this connexion that in the present series there is no correlation between change in $F E V_{1.0}$ and the initial findings of $F E V_{1 \cdot 0}$ or VC (expressed as percentages of predicted values). In patients with uncomplicated asthma and comparable ventilatory capacity findings a greater response in $\mathrm{FEV}_{1.0}$ and VC to isoprenaline might be anticipated. The comparative lack of such response and the failure of $\mathrm{FEV}_{1.0} \%$ to improve to a normal level (in all but one patient) suggest that the decreased ventilatory capacity in the present series, at least in Groups 2 and 3, is due partly to changes other than reversible bronchoconstriction. Probable factors are bronchial or bronchiolar occlusion by tenacious mucus, organic bronchiolar narrowing or obliteration and structural emphysema.

In addition to the development of structural changes in the more severely affected patients, two other factors may play a part in determining the relative responsiveness of patients in Group 2. The first is that the series as a whole may reflect the same pattern of response to a bronchodilator aerosol as Hume and Gandevia (1957a, b) found in individual patients with asthma, namely a small response (expressed in absolute units) in periods of exacerbation and of remission but a large (absolute) response in the intermediate stages. The second possibility is that the three groups reflect successive phases in the natural history of the pulmonary lesion in fibrocystic disease, Group 2 representing an intermediate phase characterized by a comparatively large component of reversible bronchoconstriction. We can offer no evidence as to the relative importance of these factors in the present series, and it must be noted that clinical wheeze was one of the criteria used to differentiate our Groups 1 and 2.

West, Levin and Di Sant' Agnese (1954) found no improvement in ventilatory capacity after Vaponefrin in the six patients whom they describe in detail. Only one other reference to the objective assessment of bronchodilator therapy is known to us: Royce (1956) referring to a 'representative' series of pulmonary function studies on one child, observed that a bronchodilator agent increased ventilatory capacity 'to a significant degree'.

In the absence of objective measurement the varying opinions to be found in the literature as to the value of bronchodilator drugs are attributable to several factors, the chief of which is perhaps the 
inadequacy of clinical methods of assessment. Audible wheezing, often taken as clinical evidence of bronchospasm, may also be due to mechanical factors such as mucous plugging, expiratory invagination of the posterior tracheal wall and bronchial collapse. This wheezing may remain after 'bronchospasm' has been reduced by a bronchodilator drug and its persistence does not necessarily mean that no alteration in the degree of bronchial constriction has taken place. Conversely, in some patients with no audible wheeze at the time of testing, considerable subjective and objective improvement may follow bronchodilator therapy, as in fact occurred in some patients in the present series.

The absence of a striking response in over half the present series should not be interpreted as indicating that bronchodilator therapy is neither indicated nor useful; even $10 \%$ improvement is worth while to a patient whose initial ventilatory capacity is a half or a third of normal. Furthermore the tests may not fully reflect an improved ability to cough up phlegm, a point which may be particularly relevant to the therapeutic use of complex aerosols. Our results in an 'acute experiment' indicate a significant though in some instances small response to isoprenaline, and a more comprehensive long-term trial of aerosol therapy is currently being undertaken.

\section{Summary}

The ventilatory capacity of 16 patients with fibrocystic disease of the pancreas was assessed immediately before and after a bronchodilator aerosol. A uniform trend towards improvement was found, more particularly in the intermediate group of children with moderate pulmonary disability as judged clinically. Improvement was less marked in children with mild or severe pulmonary symptoms. In perhaps a third of the children studied the improvement might be considered striking. The significance of these findings is briefly reviewed, and the difficulties of clinical assessment in the evaluation of bronchodilator therapy and its role are outlined.

\section{REFERENCES}

Anderson, C. M. and Freeman, M. (1958). A Simple Method of Sweat Collection with Analysis of Electrolytes in Patients with Fibrocystic Disease of the Pancreas, and their Families. Med. J. Aust., 1, 419.

Bernstein, L., D'Silva, J. L. and Mendel, D. (1952). The Effect of the Rate of Breathing on the Maximum Breathing Capacity Determined with a New Spirometer, Thorax, 7, 255

Gandevia, B. (1960). Arch. Dis. Childh. In the press.

and Hugh-Jones, P. (1957). Terminology for Measurements of Ventilatory Capacity. Thorax, 12, 290.

Hume, K. M. (1957). Personal communication.

- and Gandevia, B. (1957a). Ventilatory Capacity in Chronic Bronchitis after Oral Ephedrine. Tubercle (Lond.), 38, 199. Bronchitis after Oral Ephedrine. Tubercle (Lond.), 38, 199. Isoprenaline. Thorar, 12, 276

Royce, S. W. (1956). Cardiac and Pulmonary Complications in Fibrocystic Disease of the Pancreas. In Report of the Eighteenth Ross Pediatric Research Conference, Ross Laboratories, Ohio, p. 79.
Thompson, W. B. and Hugh-Jones, P. (1958). Forced Expiratory Volume as a Test for Successful Treatment of Asthma. Brit. med. J., 1, 1093.

West, J. R., Levin, S. M. and Di Sant' Agnese, P. A. (1954). Pulmonary Function in Fibrocystic Disease of the Pancreas. Pediatrics, 13, 155.

\section{APPENDIX}

A brief summary of the clinical history of each patient is given with particular reference to the severity of pulmonary symptoms.

\section{Group 1}

Case 1. K.R., a male of 17 years, weighing $110 \frac{1}{2} \mathrm{lb}$., was diagnosed at 9 years of age following an attack of pneumonia slow to resolve. There has been no persistent chest infection since then and he is now well grown, at work, has normal exercise tolerance, a clinically normal chest and no clubbing of the fingers. He has a palpable and firm liver.

Case 2. K.M., a female of 10 years 3 months, weight $58 \mathrm{lb}$., was diagnosed at 6 years of age. She had had abnormal stools since birth, recurrent bronchitis in winter and occasional pneumonia but no permanent cough. During the years of observation there has been no attack of pneumonia. At present she is well, has no cough, no abnormal clinical signs in the chest and no finger clubbing. She attends school regularly and has normal exercise tolerance.

Case 3. L.W., a female, sister of Case 4, 11 years 6 months, weighing $71 \mathrm{lb}$., had had abnormal stools since birth with prolapse of the rectum at times. Intermittent colds with slight cough were easily cleared by an occasional short course of an antibiotic. There has been no episode of pneumonia, her chest has been clinically clear; slight clubbing of the fingers is present. School attendance has been regular, and exercise tolerance normal.

Case 4. D.W., a female, sister of Case 3, aged 8 years, weighing $49 \mathrm{lb}$., had shown abnormal stools since early life, prolapse of the rectum and a large appetite. She has been subject to mild bronchitis in winter but has not had pneumonia nor any persistent cough. The chest has been clinically normal but slight clubbing of the fingers is present. School attendance is regular and exercise tolerance normal.

Case 5. A.P., a male aged 8 years 6 months, weighing $42 \mathrm{lb}$., was diagnosed at 6 years, having had abnormal motions and a distended abdomen since birth. There were intermittent bouts of wheezing with an attack of pneumonia at 5 years, and he had another attack of pneumonia which cleared readily at 7 years. There was no cough or wheezing at recent examinations and he had had no antibiotic therapy for one year. The chest was clinically normal. School attendance and exercise tolerance have been good. 


\section{Group 2}

Case 6. J.A., a male, aged 9 years 3 months, weighing $66 \frac{1}{2} \mathrm{lb}$., was diagnosed at 6 years 11 months following abnormal motions for 15 months with cough and sputum for two months. The chest symptoms cleared with antibiotics and since then there has been only intermittent mild chest infection. Some cough and sputum were present at the time of examination but school attendance has been regular and exercise tolerance is normal.

Case 7. D.W., a male of 12 years, weighing $87 \frac{1}{2} \mathrm{lk}$., was diagnosed at 7 years following abnormal stools since birth, recurrent bronchitis and attacks of bronchopneumonia. His chest symptoms improved with antibiotics and he is now free of cough and sputum for months at a time. When tested, some cough and sputum were present with rhonchi and rales scattered over his chest. He is a well grown boy but has finger clubbing. School attendance is fair and exercise tolerance normal.

Case 8. M.B., a female, aged 10 years 3 months, weighing $52 \mathrm{lb}$., had had offensive stools since birth and recurrent attacks of pneumonia with severe cough until the age of $2 \frac{1}{2}$ years when the diagnosis was made. She has improved gradually since then but still has some persistent cough and sputum despite continuous antibiotic therapy. Occasional rhonchi and rales are heard in the chest but were absent at the time of testing. School attendance is regular and exercise tolerance normal.

Case 9. G.P., a male, aged 7 years 9 months, weighing $43 \mathrm{lb}$., had had abnormal stools since birth with intermittent attacks of bronchitis. The diagnosis was made at the age of 4 years when he had some cough and sputum, slight clubbing of the fingers and some signs of emphysema. He improved and was relatively free of cough and sputum with continuous antibiotic therapy. At the time of testing he had occasional cough and some sputum, but no adventitiae in the lungs; school attendance has been regular and exercise tolerance is good.

Case 10. P.C., a male, aged 11 years 3 months, weighing 64 lb., had had abnormal stools since birth and pneumonia as a baby. Cough and sputum have been present nearly all his life but are well controlled with continuous antibiotics and postural coughing. $\mathrm{He}$ attends school regularly, taking part in athletics. He has emphysema of the chest with rales and occasional rhonchi and mild clubbing of the fingers. At the time of testing cough and sputum were present.

Case 11. A.N., a male, aged 15 years, weighing $67 \mathrm{lb}$., had had abnormal stools and abdominal distension since babyhood. The diagnosis was established at $7 \frac{1}{2}$ years when he had his first chest infection associated with purulent sputum. Before that occasional colds had cleared readily but now some cough and sputum is present most of the time. At the time of testing there were crepitations over the right lower lobe posteriorly, and slight clubbing of the fingers. He could produce a small amount of sputum. School attendance is fairly regular and exercise tolerance is moderately good.

\section{Group 3}

Case 12. B.M., a male, a'ged 10 years, weighing $41 \frac{1}{2} \mathrm{lb}$., had had abnormal stools together with recurrent bronchitis and bronchopneumonia. The diagnosis was made at 6 years when he was undersized, and had severe cough with sputum. He improved with continuous antibiotic therapy and postural coughing, but at the time of examination had cough and sputum with rales scattered over the chest. He attends school regularly but has only fair exercise tolerance.

Case 13. B.B., a male, aged 13 years 6 months, weighing $68 \frac{1}{2} \mathrm{lb}$., had had abnormal stools since birth and a long history of suppurative lung infection with increasing dyspnoea, emphysema and finger clubbing. The diagnosis was made at the age of $9 \frac{1}{2}$ years. Since then considerable improvement with continuous antibiotic therapy and postural coughing has occurred but at the time of testing he still had suppurative lung infection, clubbing of the fingers and emphysema. He attends school regularly but his exercise tolerance is only fair.

Case 14. G.M., a male, aged 6 years, weighing 40 lb., had had abnormal stools and distended abdomen since birth with recurrent bronchitis followed by persistent cough and sputum. He has a palpable, firm liver, emphysematous chest, clubbing of the fingers, intermittent rales and rhonchi and persistent cough and sputum. He can be controlled with antibiotics and postural coughing but home care is poor. He attends school but has limited exercise tolerance.

Case 15. P.L., a male, aged 9 years 6 months, weighing $49 \mathrm{lb}$., had had abnormal stools since birth. The diagnosis was established at 6 months. He was free of chest infection until 5 years of age. Recurrent bronchitis occurred until 6 years when he was involved in a severe car accident with injuries leading to several major surgical operations. Severe suppurative lung infection developed during this period. At the time of testing he was dyspnoeic, and mildly cyanosed with scattered rales in the chest and gross clubbing of the fingers. He attends school intermittently and exercise tolerance is severely limited.

Case 16. M.B., a female, aged 14 years 3 months, weighing $50 \mathrm{lb}$., had had abnormal stools since the first year of life and severe suppurative lung infection for about 12 years. At the time of testing she had severe dyspnoea and some cyanosis. Signs of emphysema with scattered rhonchi and rales and clubbing of the fingers were present. She does not attend school and exercise tolerance is severely limited. 